\title{
MOVIMIENTOS SOCIALES Y DEMOCRACIA: NOTAS SOBRE LA CRISIS DEL SINDICALISMO BOLIVIANO
}

ENRIQUE IBAÑEZ

\section{EL MOVIMIENTO OBRERO EN LA TRANSICION}

Diversos autores han analizado el problema de las transiciones a regímenes políticos democráticos en la década de los ochenta en América Latina destacando su carácter de "imposición" externa, o calificándolos de simple estrategia de la coalición en el poder en aras de la "gobernabilidad" del sistema. En ambos casos, la transición política aparece desvinculada de las acciones de los movimientos sociales, convertidos en contraparte pasiva de unos procesos cuya decisión y dinámica es por completo ajena a ellos. Estos planteamientos responden a la conocida atribución de una absoluta omnipotencia en la conducción de los procesos sociales del subcontinente al vecino del norte, o a los intereses de las clases dominantes; finalmente, a alguna variedad de las "teorías conspirativas".

Frente a ese tipo de análisis, cabe plantear, por el contrario, que seguramente los procesos de transición a la democracia en América Latina respondieron ante toda a una dinámica interna de estas sociedades, y que en ellos los movimientos sociales tuvieron un papel decisivo. Y esto no sólo en lo que atañe al proceso mismo de transición, sino también, y no podría ser de otro modo, en la definición de la forma en que los nuevos regímenes se han ido "consolidando". En definitiva, los movimientos sociales encontraron sus límites en los procesos de transición y consolidación democrática actualmente en curso, revelando carencias que obliguen a pensar en la necesidad de nuevas formas de organización y relacionamiento con el mundo político-partidario.

Pensemos que el caso boliviano es sumamente ilustrativo a este respecto. En primer lugar, porque la transición boliviana tuvo un carácter sumamente "abierto", de modo que su resultado no aparecía "atado" a un conjunto de pactos previos;en segundo lugar, porque los movimientos sociales, y en particular el movimiento obrero, tuvieron en ella un papel especialmente destacado; en tercer lugar, porque el sindicalismo contribuyó a promover al gobierno a una coalición de partidos políticos con los que mantenía una estrecha afinidad ideológica; finalmente, porque, a pesar de todo lo anterior, se reveló incapaz de encauzar el proceso en una dirección favorable a sus intereses.

Todos los autores coinciden en señalar (de un modo que a veces puede resultar excesivamente unilateral) el lugar central de la COB (Central Obrera Boliviana) en el proceso que condujo a la implantación de un régimen democrático en Bolivia. También se ha hecho notar en más de una ocasión la enorme paradoja que encerraron estos últimos años de la historia del país: el sindicalismo boliviano entró en la mayor crisis de su historia en el momento en que empezaba a consolidarse el régimen político por el que tanto había luchado.

Las "contradicciones" del "reformismo" que enarbolaba el primer gobierno democrático (La UDP, una coalición de fuerzas de izquierda), en una sociedad extremadamente polarizada y con un poderoso movimiento obrero fuertemente readicalizado, hicieron prever a algunos 
analistas la posibilidad de que el caótico proceso de transición desembocara en una auténtica revolución social. Es sabido que, por el contrario, aquellas "contradicciones" desembocaron en un aplastante triunfo electoral de la derecha que, tras enfrentar y derrotar al movimiento obrero, implantó un programa de ajuste regresivo que alteró radicalmente las bases materiales de la acción colectiva popular. Al mismo tiempo, redefinió las reglas del juego, situando a la esfera parlamentaria como lugar exclusivo de la política, y marginando así a la otrora todopoderosa $\mathrm{COB}$ de los procesos de toma de decisiones.

En el breve espacio de este artículo intentaremos dar algunas pautas para comprender un proceso que puede verse como variante extrema de un tema común latinoamericano. La crisis en que han ido entrando los movimientos sociales de todo el subcontinente ante el impacto combinado de las políticas de ajuste $y$ de las transformaciones en los sistemas políticos, adquirió en Bolivia tintes especialmente dramáticos. Por ello, creemos que analizar las condiciones en que el sindicalismo boliviano se enfrentó al escenario de los años 80 y los diversos determinantes de la dinámica que lo condujo a su actual colapso, puede aportar algo a quienes se interesan por definir lo general y lo específico de unos procesos que afectan hoy a todos los países de América Latina.

\section{LA COB Y LA DEMOCRACIA: LA CULTURA POLITICA DEL SINDICALISMO BOLIVIANO.}

René Zavaleta recordaba la inexistencia de una tradición de compromiso con la democracia política en el seno del movimiento obrero boliviano. Por ello resultaba tan llamativa la postura que adoptó la $\mathrm{COB}$ en el tramo final del gobierno de Bánzer, especialmente visible durante el golpe de Natusch y en los años que transcurrieron hasta el ascenso de Siles (octubre de 1982), que muchos en la izquierda calificaron como "electoralismo" estrecho. Ciertamente, el rechazo de la propuesta de co-gobierno hecha por Nastusch en noviembre de 1979, y la apuesta cobista por la legalidad parlamentaria, parecía indicar que algo muy profundo había cambiado. Como recuerda Zavaleta, los momentos históricos que la memoria popular retenía como "democráticos" no hacían ninguna referencia al marco institucional, sino sólo al contenido más o menos "popular" de los regímenes, a su actitud hacia el movimiento obrero.

Sin embargo, por debajo del espectacular cambio de actitud de la $\mathrm{COB}$, es fácil descubrir un conjunto de continuidades en la "cultura política" sindical que dificultarán la relación del movimiento obrero con el nuevo régimen político y con el primer gobierno democrático. Varios autores han hecho hincapié en este punto, al señalar la responsabilidad que tuvieron la ideología política, la visión del mundo y las pautas normativas que regulaban el comportamiento sindical (escasamente compatible no sólo con el juego democrático sino con cualquier forma de política "secular") en el desencadenamiento de la espiral de conflictos que durante el gobierno de la UDP disparó la escalada hiperinflacionaria, acelerando la crisis económica que atravesaba el país $\mathbf{y}$ deslegitimando así el sindicalismo y con él a toda la izquierda política.

Hablamos de una cultura política, en la que Felipe Mansilla cree descubrir una peculiar mixtura de elementos del marxismo milenarista y otros heredados de la tradición autoritaria del mundo hispano-andino, que define la política como lugar de la guerra, negando la posibilidad de la negociación y 
el compromiso, fundamentos de la regulación democrática de los conflictos. La evolución de las numerosas negociaciones y de los fracasados intentos de concertación entre la UDP y la COB, podría ilustrarnos sobre este punto. En el interior del discurso obrero, "concertación" o "negociación sólo podrían entenderse, según Jorge Lazarte, como imposición del criterio propio al adversario derrotado. Dentro de esta lógica militar, cuya prevalencia en el movimiento obrero boliviano se debería a una larga historia de resistencia frente a gobiernos siempre autoritarios, el único factor a tener en cuenta es la correlación de fuerzas en cada momento. En la etapa de gobierno izquierdista ésta era siempre favorable a la COB, que se enfrentaba a un adversario extremadamente débil (ante todo porque su legitimidad se fundaba en su carácter "popular", cuando la COB era expresión de "lo popular"), y el resultado de las "negociaciones" solía ser siempre el abandono gubernamental de las líneas maestras de su política económica. El país se introdujo así en aquella perversa dialéctica de los sucesivos "paquetes" que nunca podían ser aplicados, mientras todas las variables macroeconómicas se precipitaban en un deterioro incontrolable.

El problema sería el siguiente: la COB reprodujo en el gobierno de Siles pautas de acción y estrategias de conflicto heredadas de una etapa definida por la exclusión política (el gobierno era el único responsable de las decisiones y de sus resultados), y por un crecimiento económico que permitía a la coalición dominante asumir las demandas obreras. Pero resulta evidente que en un contexto que se había alterado de un modo radical por el doble impacto de la crisis y de la transición (entrada en un escenario de recesión económica y participación política), el radicalismo cobista solo podía resultar suicida. En este sentido el movimiento obrero los boliviano compartió un problema común a sectores populares de todo el subcontinente en el nuevo escenario de los años 80: su herencia histórica funcionó como una "anteojera" que le impidió percibir la especificidad de la nueva coyuntura y lo que se juzgaba en ella.

No cabe dudar de la importancia que tuvieron la "cultura política" o los hábitos del movimiento sindical como determinantes de las conductas "irracionales" de la dirigencia de la COB en la etapa de gobierno izquierdista, que no podrían entenderse sin apelar a ella. Pero las explicaciones habituales del comportamiento del sindicalismo boliviano en democracia pecan a nuestro entender de una excesiva unilateralidad. Al privilegiar como casi única variable explicativa del comportamiento de los actores su "memoria larga", al considerar que éstos repiten mecánicamente modelos de acción heredados del pasado y amparados en una "cultura política" que los legitima y dirige, descuidan el análisis de otros elementos imprescindibles para dar cuenta del accionar del movimiento social.

Es cierto que el pasado, lo que uno ha sido y las experiencias que uno ha conocido, tiende a persistir e incluso a modelar las percepciones y los comportamientos de los actores en los mismos momentos en que todos los datos de su entorno social se alteran por completo. Estudiar la adecuación o inadecuación de la "culturas" y los modelos de acción heredados a la coyuntura presente, debe ser por tanto un terreno privilegiado de investigación para quienes nos interesamos en la suerte de los movimientos sociales. Pero creemos que no hay ninguna razon para suponer "a priorl" que estos elementos vayan a actuar en forma homogénea ni a determinar las representaciones y decisiones de los actores de un modo inmediato e independiente de los contextos situacionales en que aquellas tienen lugar. 
Por otro lado, no hay que desculdar el análisis de un conjunto de variables estructurales que conforman la herencla "material" que el movimiento social recibe en la coyuntura, más allá de su "memoria" o de su "cultura política". A este respecto, creemos que en los trabajos sobre la evolución reciente del movimiento obrero boliviano, el "mito" del poder de la COB ha dificultado una evaluación serena de su representatividad real, de la influencia efectiva de las dirigencias sobre las bases del movimiento social, y del grado de homogeneidad interna de aquéllas, variables que incidieron en la capacidad de la organización para controlar el conflicto social e imponerle una dirección estratégica coherente. La idea más extendida es que la COB tenía capacidad para dirigir el conflicto social, para encauzar el proceso en un sentido favorable a los intereses populares, y que el problema estuvo estuvo en sus decisiones estratégicas irracionales, derivadas de su "cultura política". Como veremos -con la brevedad y la superficialidad que impone la extensión de este trabajo-, esto no es en absoluto evidente.

\section{TRANSICION "ABIERTA" E INCER- TIDUMBRE}

Los últimos años del régimen autoritario boliviano se caracterizaron por un grado de desorden que seguramente no tiene paralelo en los otros procesos de transición que se han ido desarrollando en el subcontinente. Con la camarilla de García Meza, los intereses del narcotráfico se introdujeron en todas las esferas del gobierno; los empresarios se desvincularon por completo del régimen, incapaz de desarrollar ninguna política económica mínimamente ordenada y sometido a un aislamiento internacional absoluto, mientras la recién constituida central sindical independiente de campesinos, los obreros, mineros y estudiantes ejercían una creciente presión sobre un gobierno cada vez más inefectivo. Finalmente, el plazo y la forma (la convocatoria al Congreso de 1980 en lugar de la celebración de nuevas elecciones) de la entrega del gobierno a los civiles fue impuesto por un movimiento huelguístico en las minas que contó con un amplio apoyo urbano. Siguiendo a Whitehead, el "carácter corto de miras, indiscriminadamente represor y parasitario del régimen saliente, la redemocratización de mediados de 1982 fue un proceso claramente planificado y sin orden". El progresivo envilecimiento de los gobiernos militares había ido provocando rupturas en las FF.AA., y a medida que iban emergiendo reclamos sociales reprimidos se fue perdiendo todo control sobre lo que había comenzado como una liberalización "controlada".

Junto al carácter caótico y violento de la transición boliviana, la polarización ideológica de las fuerzas políticas contribuyó en gran medida a que en el país no se conformara una "alianza democratizadora" estable. Los partidos políticos optaron por el enfrentamiento $y$ no concretaron ningún conjunto de pactos sobre las nuevas "reglas del juego". Estos desarrollos supusieron, como recuerda Whitehead, "la posibilidad de una transición electoral a un régimen constitucional, no manejada y auténtica". Pero también, y es importante tenerlo en cuenta, la entrada, durante el primer gobierno democrático, en una coyuntura de crisis institucional permanente, en la que cualquier resultado parecía posible. Los empresarios demostraron desde el principio una escasísima "lealtad" al nuevo gobierno, al que consideraban potencialmente peligroso para sus intereses, y las amenazas de un nuevo golpe se sucedían casi cada mes.

EI análisis detallado de este contexto debería hacernos matizar la atribución 
mecánica a la "cultura política" sindical de la responsabilidad por la conducta "irracional" del movimiento social en el período del gobierno de la UDP. Se trata de señalar que en una coyuntura crítica como la que caracterizó a la transición boliviana se produce inevitablemente una multiplicación de la "incertidumbre estructural" de que nos habla la teoría de juegos. En semejante contexto, los actores sociales ven reducida su capacidad tanto para anticipar las líneas de acción de sus adversarios o de sus eventuales compañeros, como su capacidad para identificar o definir la situación en la que se encuentran. El desmoronamiento de cualquier certidumbre mínima sobre el futuro, al que se enfrentan los protagonistas de la crisis, contribuye a una inhibición tendencial de la actividad estratégica. Al reducirse el control que los actores tienen sobre el alcance de sus propios actos y sobre su significación en el curso de la confrontación, éstos tienden a refugiarse en posturas puramente defensivas, intentando así reforzar su identidad. Miran, en fin, hacia el único lugar que puede ofrecerles entonces la certidumbre que necesitan: su propio pasado. Creo que es aquí donde hay que buscar una de las claves para explicar el diferente peso de la "cultura política" y de la "memoria" en la formación de las decisiones del movimiento obrero boliviano $y$, por ejemplo, del chileno, en el nuevo escenario democrático.

\section{Utilizando expresiones de Laclau,} podríamos decir que en un contexto como el descrito, las estrategias de pura oposición se imponen abrumadoramente a cualquier "estrategia de construcción de un nuevo orden". EI colapso de la actividad estratégica coloca en un primer plano a las políticas de enclave, ya ideológicas, ya corporativas, inhibiendo la acción estratégica constructiva. Esta es sin duda, más allá de su cultura política, una de las causas del continuo repliegue de la $\mathrm{COB}$ hacia actitudes cada vez más estre- chamente salarialistas, así como de su "irracional" escalada reivindicacionista frente a un gobierno con el que en principio compartía el mismo proyecto.

De la problemática aquí presentada deberíamos poder derivar, aparte de alguna indicación metodológica, la necesidad que tiene el movimiento popular de adoptar un compromiso profundo con los procesos de consolidación institucional, participando activamente en los proyectos de reforma política. El movimiento obrero debería tener el mayor interés en la concreción de sólidos "compromisos de sistema" y en su institucionalización progresiva, y esto es algo que hoy todavía no ha asumido la COB. Adam Przewoski ha destacado la importancia que tuvo en el "compromiso de clases" que según él cimentó la "profundización" de la democracia en los países del norte de Europa, la existencia de un contexto institucional estable. A pesar de que se podría replicar -utilizando al mismo Przewoski- que la existencia de un marco democrático consolidado no es garantía de casi nada, cabría seguir pensando que seguramente es el punto de partida ineludible para la construcción de cualquier política que podamos identificar como progresista.

\section{DEFICIT DE REPRESENTATIVIDAD}

Es ya costumbre en los análisis de la dinámica de la historia boliviana reciente comentar el "desequilibrio" que se dio en el país entre su profundo subdesarrollo económico y su "modernidad" política. No hay espacio para discutir aquí los presupuestos sobre los que habitualmente se atribuye una gran "fortaleza" a la "sociedad civil" boliviana y particularmente a su movimiento obrero, pero debemos decir algo sobre esto último, dada 
la importancia que tiene esclarecer este punto para entender en toda su dimensión los problemas que enfrentó la central obrera en la coyuntura democrática.

En primer lugar, hay que hacer notar que se ha tendido a confundir la existencia de una fuerte "subcultura obrera" en las minas, promovida por un aislamiento social y geográfico que configuraba una situación "comunitaria", con la de una "conciencia política socialista" que se suponía además arraigada en buena parte del proletariado boliviano. En segundo lugar, no se valoró lo suficiente el hecho de que la fuerza de la COB dependía críticamente de la situación estratégica de los mineros en un modelo de desarrollo minero-exportador que estaba en decadencia desde hacía más de una década. Finalmente, se tendió a identificar la presencia en diversas coyunturas históricas de un amplio público que apoyaba los valores generales reivindicados por la Central Obrera ("participación popular", "democratización"), con la influencia efectiva que ésta tenía sobre el espectro social.

Creemos que la dinámica del conflicto social en el período de gobierno de la UDP demostró lo infundado de aquéllas suposiciones. La COB resultó ser una organización enormemente inefectiva, en tanto que su influencia, su capacidad de dirección real del conflicto, no alcanzaba a la mayoría de los sectores asalariados. Atendiendo a esto podemos dar cuenta de aspectos de la dinámica del conflicto social bajo el primer gobierno democrático que no se podrían entender desde la ecuacion simplista que deriva la acción directamente de la "cultura política" y el hábito. Así podemos explicar por qué los mineros (el sector sin duda más permeado por aquélla cultura reivindicativa "radical") contuvieron sus demandas inmediatas, mientras otros sectores se introducían en la espiral de conflictos salariales. En las minas, la dirigencia de la Central Obrera si tenía una auténtica capacidad de dirección, fundada ante todo en una lealtad "tradicional" de las bases hacia sus representantes, que no existía sin embargo en el seno de otros sectores. En la mayoría de los casos, la Central Obrera debió limitarse a "apoyar" conflictos que se desencadenaban con total independencia de las decisiones de la dirección nacional, intentando así mantener incuestionada su "representatividad". Para los dirigentes de la COB era materialmente imposible hacer cumplir a las bases los compromisos que asumían con el gobierno, y es fácil apreciar cómo sus decisiones estratégicas irracionales tuvieron tanto o más que ver con su incapacidad para controlar efectivamente el conflicto social, que con el "milenarismo" que embotaba sus cerebros.

La debilidad que el sindicalismo boliviano reveló en la coyuntura democrática tiene que ver sin duda con un conglomerado de elementos ideológicos y organizativos sobre los que convendría reflexionar. Así, el famoso "pluralismo" de la COB derivó en una aguda competencia intraelitaria que contribuyó a "calentar" el conflicto social; la sobrerrepresentación anacrónica de los mineros y otros proletarios "auténticos" en el ejecutivo de la central disminuyó la posible influencia de los dirigentes sobre la totalidad de los sectores asalariados; finalmente, el respecto irrestricto de la democracia basista dificultó la adopción de estrategias coherentes por parte de una dirigencia sometida a la constante presión de las bases.

Desde luego, los problemas organizativos del movimiento obrero boliviano son complejos, y no cabe decir aquí nada definitivo sobre ellos. Creemos, sin embargo, que una relación más estrecha con los partidos políticos de dimensión 
nacional debería limitar la influencia que conserva en el seno de la $\mathrm{COB}$ un conjunto de grupúsculos radicalizados, que no tienen ninguna presencia fuera de la organización matriz de los trabajadores $y$ por ello compiten fuertemente por hacerse con un lugar en su interior, con las consecuencias nocivas que se hicieron evidentes en el gobierno de la UDP. Es necesario, desde luego, un cambio en la composición de los órganos ejecutivos del sindicato que los acerque a una estructura de clases que ha sufrido una alteración radical. En esta dirección debería poder avanzarse más rápidamente, aunque la brutalidad de la respuesta "proletaria" a los reclamos campesinos en el último congreso nacional nos recuerda que aún existen fuertes resistencias al abandono de los prejuicios vanguardistas.

Para terminar, cabe plantear la necesidad de buscar mecanismos que equilibren la necesaria democracia interna con la también necesaria autoridad de los dirigentes mediante el desarrollo de relaciones de confianza, y esto no se logrará mientras se mantenga una mística basista que convierte inmediatamente en sospechosa traición a cualquiera que se encuentre por encima de la base.

Pero más allá de los problemas organizativos que acabamos de mencionar, la experiencia histórica de la $\mathrm{COB}$ nos habla de la disfuncionalidad de su propuesta "sindicalista" para la "construcción de un orden" progresivo en una sociedad signada por la radical heterogeneidad de sus sectores populares. La COB no pudo cumplir con las tareas que se autoasignaba al proclamarse "actor mixto" (a la vez representación corporativa de los trabajadores y expresión política de lo popular), y nada es tan urgente hoy como recomponer una "mediación política" capaz de articular la dispersión del campo popular. En el actual contexto institucional los partidos aparecen como el canal privilegiado de agregación de demandas y formulación de políticas, pero conviene tener presente que esa misma heterogeidad de los sectores populares que hizo del "sindicalismo" una propuesta inviable, nos previene contra la tentación de trasladar mecánicamente a Bolivia las recetas socialdemócratas clásicas. Imaginar las formas de mediación política adecuadas a la estructura social y a la tradición histórica bolivianas es todavía un desafio pendiente.

\section{RESUMEN}

El caso boliviano demuestra el papel decisivo jugado por los movimientos sociales en los procesos de transicion democrática. Asi como sus carencias atribuidas a la peculiar "cultura política" del movimiento obrero boliviano. Sin embargo un análisis del contexto de la transición - caótico, violento y con fuerte polarización ideológica - exige la consideración de un conjunto de variables estructurales. La multiplicación de la "incertidumbre estructural" favoreció la inhibición de la acción estratégica constructiva de la COB que junto a las disfuncionalidad de su propuesta sindicalista en una sociedad heterogénea, explica la incapacidad de la central para encauzar el proceso en favor de sus intereses. Se sugiere la urgencia de recomponer la mediación política capaz de articular la dispersión del campo popular mediante fórmulas adecuadas a la estructura social y a la tradición histórica boliviana.

\section{ABSTRACT}

The bolivian case shows the decisive rol played by social movements in the proceses towards democracy, so as their lacks, due to the peculiar "political culture" in labor movement. Nevertheless a further analysis of the transition environment - caotic, violent and with a high polarization - has to take into account a set of structural variables. So, the multiplication of structural uncertainty favourend the inhibition of the strategic constructive action of COB that added to plus disfuncionality of the union proposals in a heterogeneous society, explain the union uncapability for guiding the process towards its own interests. Its also suggested the urgency of rebuilding the political mediation capable of structuring the dispersed popular sector by means of suittable formulas to the social structure and historic traditions of Bolivia. 